

\title{
Refletindo de volta
}

\author{
Marilyn Strathern ${ }^{1}$ \\ Tradução: Janaina Tatim
}

\section{Resumo}

Este convite apresenta uma oportunidade de reunir vertentes mais antigas e mais recentes do trabalho sobre relações. A primeira remetia a uma noção analítica de estética para transmitir certos tipos de aparências persuasivas: a etnografia melanesista enfatizou o quanto importava que as relações assumissem uma forma adequada (reconhecer o apoio dos ancestrais por exemplo). A segunda é uma crítica recente às relações enquanto um conceito euro-americano explícito em um de seus contextos vernáculos, nomeadamente, o uso em inglês. Aqui, os tipos de interesses amerindianistas nos quais o dossiê desta revista se engaja - e conforme colhidos em certas traduções para o inglês -, me levam a localizar um efeito estético na penumbra das conotações e associações que munem as relações (em inglês) de uma aura ou atmosfera. O que antropólogas e antropólogos normalmente descartam quando constroem seus vocabulários analíticos se torna interessante.

Palavras-chave: Relações; Efeito Estético; Forma; Melanésia; Pensamento euro-americano

\section{Abstract}

This invitation presents an opportunity to bring together older and newer strands of work on relations. The first fell back on an analytical notion of aesthetics to convey certain kinds of persuasive appearances: Melanesian ethnography emphasized how much it mattered that relations took an appropriate form (recognizing the support of ancestors for example). The second is a recent critique of relations as an explicit Euro-American concept in one of its vernacular contexts, namely English usage. Here, the kinds of Amerindianist interests engaged by the special issue of this journal - and as gleaned from certain translations into English - lead me to locate an aesthetic effect in the penumbra of connotations and associations that endow relations (English-speaking) with an aura or mood. What anthropologists ordinarily dismiss when they construct their analytical vocabularies becomes interesting.

Keywords: Relations; Aesthetic Effect; Form; Melanesia; Euro-American Thought

1 Professora da Universidade de Cambridge e Doutora em Antropologia pela mesma instituição. E-mail: ms10026@cam.ac.uk. 
Ao situar as relações no cerne da síntese melanésia (Strathern, 1988), eu estava, é claro, fazendo a crítica de um par de conceitos euro-americanos (indivíduo, sociedade) com outro conceito (relações) igualmente abstrato. Voltando ao argumento, agora fico impressionada com o papel metodológico, ou mais apropriadamente expositivo, que a estética desempenhou nele. Os efeitos estéticos emergiram simultaneamente como um registro de certas formas locais (de ser, agir) e como um registro das intenções expositivas da escrita antropológica. Talvez essa seja uma peculiaridade do conceito: nenhum "efeito" foi descrito se quem escreve falha em transmiti-lo, pelo menos em parte. Desse ponto de vista, ofereço alguns comentários sobre a estética das relações.

\section{Reflexões ameríndias e melanésias...}

Os melanésios não nomeiam - não têm um termo para - relações (Crook, 1997: 28), e o mesmo foi observado em um contexto amazônico (Vanzolini, 2019: 10); o/a antropólogo/a as infere. No entanto, a sensibilidade melanésia quanto a aparências, eventos e acontecimentos que assumem uma forma convencional, e, portanto, reconhecível, pode vir a ser um recurso analítico para demonstrar várias maneiras pelas quais as pessoas, ao que parece, fazem conhecer relações entre si. No meu caso (Strathern, 1988: 187), uma infinidade de outras abstrações ludibriou a dificuldade técnica em descrever o que a antropóloga precisava tornar aparente. Talvez meu apelo a um registro estético, chamando atenção à adequação de formas específicas, fosse algo como uma tentativa de abrir à equivocação controlada (para o que eu então não tinha nome!) os termos analíticos de outro modo desapercebidos que se seguiram, tais como troca, plantação, criação, clã e assim por diante, todos com relações implícitas.

De modo geral, pensar sobre as formas que relações assumem oferece uma espécie de tradução interna para o/a antropólogo/a daquilo que já é parcialmente apreendido por outros meios, e que vai se aplicar de inúmeras maneiras em configurações cambiantes (Di Giminiani e González Gálvez, 2018: 200-201; Lagrou, 2019: 26). A propósito dos Urarina peruanos, Walker lista várias relações (termo meu) pelas quais ele reconhece uma recusa geral de equivalência no trato das pessoas umas para com as outras, como a convenção de se presumir a ilegibilidade das intenções dos outros ou a volatilidade nas disputas: "Meu amigo num dia é meu inimigo no outro" (2020: 154). Ele sugere que tal "recusa" se fundamenta em uma noção expandida do comum, o que as pessoas sentem que as fundamenta, o que abrange todos os tipos de diferença ${ }^{2}$. Em consonância, Costa e Fausto (2019) argumentam que os/as antropólogos/as deveriam ser cautelosos com aquelas relações que podem reconhecer fácil demais. Importa, por exemplo, a que campo relacional alguém assimila as relações interespecíficas na criação de animais de estimação na Amazônia, uma vez que isso se torna uma questão de saber de que conceitos elas (as relações) vêm acompanhadas. Para Costa e Fausto, ter animais de estimação não é mais uma variedade de

2 Colocando de outro modo, estar relacionado através da diferença não precisa empregar medidas de similaridade e dissimilaridade. 
domesticação do que seus mestres são proprietários soberanos. As formas introduzidas através de tais (re)descrições se voltam a julgamentos de adequação conceitual. A maneira pela qual a adequação é registrada, seja na sensação de bem-estar das pessoas, seja na persuasividade de uma configuração analítica, poderia ser considerada uma resposta de tipo estético.

Dito isso, relações já particularizadas por seu contexto ou uso são uma coisa; há lugar para uma resposta estética à(s) relação(ões) ${ }^{3}$ como uma abstração ou generalidade, já que o termo também é empregado em inglês? Eu não tinha pensado na questão antes, mas é concebível que o emparelhamento melanésio de entidades interrelacionadas (simetricamente ou não) que representa a necessidade de estar em relação (Strathern, 1988: 188; Moutu, 2013: 202) pudesse ser imaginado dessa forma. Mais direto ao ponto, considere a recente versão de Lagrou (2019) da estética relacional ameríndia conforme é tecida, pelos Huni Kuin, em grafismo e música. Ela abstrai disso uma condição mais geral de estar em relação, a "entremeabilidade" ["the betweenness"] de todos os seres, a qual ativa o potencial sempre multiplicador de um ser para incorporar um outro (ser) que, de outra forma, o incorporaria 5 . Para os Mapuche, Giminiani e González Gálvez (2018: 200) delineiam "um tipo ideal de relação" que entendem como "objetivação incompleta ou inacabada", enquanto que para os seres vivos "estar em uma relação" é em termos Paumari "ser capturado" (Bonilla, 2016: 126). Então, é claro, Vanzolini (2019: 105) nos lembra a percepção de Viveiros de Castro (2004) de que nos mundos amazônicos uma forma comum de relação é a figura traduzida como "cunhado" ou "primo cruzado", que, nas palavras de Vilaça, contém em si “o princípio da diferença entre os termos relacionados" (2019: 147). Embora a personificação da diferença possa ser verdadeira sobre a afinidade em geral, a especificidade do cunhado parece de um momento estético particular na descrição (antropológica) original. Ela reúne tudo em uma única imagem - e gera uma contraparte etnográfica/analítica.

O que surge em contrapartida ao cunhado [brother-in-law] é o irmão [brother], pois "a

3 É uma complicação expositiva em inglês que a forma plural de relação também se refira a relações em geral e, portanto, a um conceito no singular.

4 Nota da tradutora: optei por uma tradução diferencial entre esse uso do termo "betweenness" e o uso que a própria autora vai distinguir em termos conceituais (ver nota seguinte). Aqui, opto por entremeabilidade por remissão ao verbo entremear também usado como sinônimo de trançar e permear, remetendo, assim, ao gesto dos Huni Kuin de reversão/transformação no canto, grafismo e tecelagem. Já com "intermedialidade” para a outra noção de "betweenness" procurei remeter à ideia de mediação, de que entre um ser e outro há o espaço da mediação, pois trata-se de evidenciar o elo, a capacidade de dois seres descontínuos ("self-contained") se ligarem um ao outro por meio de algo.

5 Como em ver por ser visto, ingerir por ser ingerido. Dada sua referência ao "tornar-se um eu por meio do tornar-se outro" (Lagrou, 2019: 37; ver González Gálvez; Di Giminiani e Bacchiddu [2019: 7] - compare ao par irmão mais velho/mais novo de Moutu [2013]) - o que ela chama "entremeabilidade" ['in betweenness'] parece se referir a um estado de ser em devir [ever-becoming state of being]. Deve-se distinguir isso da "intermedialidade" [the 'betweenness'] que traduz "a relação como a ligação entre duas unidades independentes [self-contained]" (Gi Gimiani e Conzález Gálvez, 2018: 202), que é seu uso dominante em inglês (ver Strathern, 2020). 


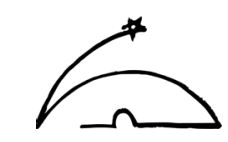

fraternidade é [...] a forma geral [ocidental] da relação" (Viveiros de Castro, 2018 2 : 261)7. E então o mundo gira em torno de seu eixo, uma vez se presume que este último tipo de irmãos ${ }^{8}$ sejam semelhantes, minimamente a medida que sua semelhança é vinculada pela mesma relação para com um terceiro. Inserido como está na linguagem euro-cristã, recorrer a tal termo (irmão) para um conceito antropológico (relação) também cria um efeito estético?

... e ...

Comparações com o uso euro-americano transcorrem nesse punhado de escritos amerindianistas. Desnecessário dizer que o problema é a linguagem da descrição. Mas o que fazemos com o fato de que os euro-americanos realmente têm um nome ou termo para relação(ões) ${ }^{9}$ e, de modo geral, com o fato de que o uso analítico é caracterizado pela abstração? Que apelo conceitual existe, no decorrer da escrita ou da compreensão, para os efeitos estéticos, então?

$\mathrm{Na}$ ausência de termos locais específicos, descrever o senso de um/uma interlocutor/a da adequação de certas formas de existência pode dar um contorno ou levar a algum lugar formulações antropológicas que de outro modo restariam difusas na familiaridade do consenso teórico ou da linguagem cotidiana. - Relação como cunhado: é preciso parar e pensar. - Ao contrário, diante de um conceito cujos termos já estão moldados e apontados por serem nomeados (digamos), o/a antropólogo/a pode se surpreender com efeitos estéticos em outros lugares. Isso não quer dizer que um conceito abstrato não possa ter forma (e eu dou um exemplo abaixo), mas sim sugerir que pode haver algum potencial em considerar muito do que os acadêmicos normalmente veem como uma diminuição da força denotativa de termos consensuais. Refiro-me à penumbra vernacular da conotação, aos valores, tonalidades e coisas semelhantes, seja se ficam coladas a certas expressões, ou se trocam e mudam com esta ou aquela situação. Assim, no caso do "irmão" euro-americano para "relação", poderíamos dizer que a figura fraterna pertence a todo um conjunto de imagens, que não apenas figuram uma base comum para as relações, mas também (por exemplo) dão uma aura de afeto positivo à noção de similaridade. As conotações são sempre discutíveis e facilmente descartadas do discurso formal. Diante disso, pode ser necessário algo como a demonstração de

$6 \quad$ Nota da tradutora: Marlyn Strathern cita a partir do artigo originalmente em inglês (Viveiros de Castro, 2004: 18). Utilizamos aqui a tradução de Marcelo Giacomazzi Camargo e Rodrigo Amaro publicada no Brasil: Viveiros de Castro, Eduardo. 2018. "A Antropologia Perspectivista e o método da equivocação controlada". Aceno - Revista de Antropologia do Centro-Oeste, 5 (10): 247-264. https://periodicoscientificos.ufmt.br/ojs/index.php/aceno/article/ view/8341

7 A sequência em tempo real pela qual Viveiros de Castro (2018: 259-261) chegou à "adequação" de uma tradução equivocal de cunhado como irmão é repassada no posfácio de Vilaça (2019) para um número especial sobre a teorização de relações na América do Sul indígena (ver González Gálvez, Di Giminiani e Bacchiddu, 2019). Os comentários de um dos pareceristas da revista Maloca me fazem perceber a extensão em que essas formulações sobre "irmãos (cunhados)" ["brothers (in-law)"] dependem terminologicamente, se não conceitualmente, das possibilidades em inglês em oposição ao português.

8 Nota da tradutora: em inglês, o termo para cunhado, "brother in-law", literalmente, irmão pela lei, contém em si irmão, daí a noção de que, em inglês, cunhado expressa um tipo de irmão.

9 E o nome tem como objetivo identificar; ver a discussão crítica de Vanzolini (2019: 113-115) a propósito dos nomes pessoais. 
um efeito estético - tornar uma estética vernácula de interesse analítico - para trazê-las (as conotações) ao primeiro plano no trabalho de modelagem que fazem.

Com o uso em inglês vernáculo de relações como meu exemplo euro-americano, volto-me agora a algumas conotações de semelhança. Primeiro, porém, a uma forma para abstração.

\section{... algumas euro-americanas}

Um esforço imaginativo para dar forma visual às relações conceituais é apresentado através do diagrama (Holbraad, 2020). Enquanto Holbraad chama a atenção para inúmeras modulações das relações, a visualização é exemplar de uma resposta estética, nesse caso, para conceitos que se manifestam como abstrações. O conceito é trabalhado por meio de outra configuração abstrata, ou antes, a configuração de uma forma abstrata. O diagrama dá à abstração uma forma ${ }^{10}$.

Holbraad aborda explicitamente a contínua necessidade de invenção conceitual da antropologia: a sensibilidade antropológica é acima de tudo "um tipo de estética intelectual" (2020:4) que dá aos fenômenos etnográficos formas conceituais particulares, e com consequências transfigurantes. Eu comentaria sobre como os diagramas alcançam esse efeito enquanto selecionam diferentes elementos, como aqueles que compõem uma relação, os quais podem então ser representados como em movimento relativamente um ao outro. Assim, ele mostra como a compreensão antropológica da dádiva de Mauss (especificamente das relações implicadas na reciprocidade) se metamorfoseia de um conceito de coisas que passam entre pessoas, para um de pessoas que se ampliam em relação umas às outras. Com efeito, pessoas e coisas mudam suas posições ideacionais, demonstradas por meio de diagramas imaginados como uma série que reorganiza sequencialmente a "entremeabilidade" [the "betweenness"] desses elementos. Esse rearranjo de elementos sugere que em abstrato a relação pode ser estetizada como um modelo de trabalho com partes.

Deixo esse espaço imaginativo afim de me voltar a modos não visuais de apreensão, conforme funcionam em inglês vernáculo, e de sensibilidades que são antes uma questão de disposição ou afeto. É óbvio que as relações vão adquirir numerosas conotações em constante mudança a partir das circunstâncias particulares de uso. Ao mesmo tempo, valores ou atributos podem se associar ao próprio conceito em si, criando uma atmosfera padrão, por assim dizer, que pode comprometer um uso mais neutro ${ }^{11}$. Assim, relações são comumente consideradas benignas ou interessantes antes de serem malignas ou sem interesse.

Um conjunto de tais atributos ajuda a formar uma aura positiva em torno das próprias relações, em língua inglesa. Ao servir para aproximar entidades ${ }^{12}$, oferecem um senso de proximidade,

10 É importante em sua descrição que, na medida em que a busca é de relações conceituais, "aquele que analisa tem de imaginar para poder descrever (...) os fenômenos" (Holbraad, 2020: 21, ênfase omitida), a abstração não está - como ele coloca - distante da vida, mas se movendo em direção a ela.

11 Isso é particularmente verdade nas relações interpessoais. No inglês comum, as relações antagônicas entre as pessoas podem ser imaginadas como uma ausência de relação, enquanto participar de relações pode ser considerado "sentimental" ou "suave". O que se segue vem de um trabalho mais longo (Strathern, 2020), onde o aqui inexplorado entrecruzamento das relações interpessoais e epistêmicas é discutido de forma mais completa.

12 Sigo a ênfase vernácula nas relações como, antes de mais nada, entre entidades distintas, criticada e evitada

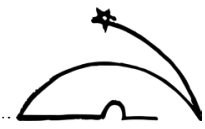




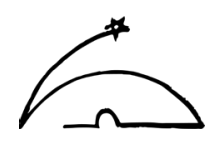

de semelhança ou similaridade, de associação ou comparabilidade. Esses atributos podem ser ainda mais personificados no que respeita às relações interpessoais ${ }^{13}$, evocando expectativas de amabilidade, sociabilidade, camaradagem ou companhia. Se isso começando a soar amigável demais, lembremos da observação de Viveiros de Castro (2015 [2000 14 ]: 110) de que ver "o mundo irradiar de uma intimidade socialmente positiva a uma distância socialmente negativa" corresponde a um modelo ocidental egocentrado da vida social "no qual o protótipo da relação é a autoidentidade", o ponto mais íntimo. A relação consigo mesmo funda toda relação com o outro, notadamente no caso do amigo (depois de Aristóteles) como um outro eu, "um outro mas um outro como um 'momento' do eu" (2015: 185). Na filosofia ocidental, essa figura do amigo foi elucidada como uma alteridade fundacional intrínseca à conceituação e ao pensamento como tal. Na linguagem comum em inglês, a amizade carrega um certo teor de sociabilidade, especialmente aquela promovida por uma "sociedade de semelhantes" ou da "equivalência de indivíduos" (Walker, 2020: 149). A amizade é de interesse nesse contexto, na medida em que esse tipo de teor muitas vezes parece saltar para o fundo das relações.

"[A]mizade é a principal alegria da vida humana", e a estima e o afeto dos amigos constituem a "parte principal da felicidade humana", disseram David Hume e Adam Smith em meados do século XVIII (Rasmussen, 2017: 5). Cada um nesse par de filósofos do Iluminismo considerava o outro seu melhor amigo ${ }^{15}$. Já escrevi em outro lugar sobre a convivialidade e a simpatia que Hume, em particular, inspirou em sua teorização das relações, a qual se voltou para como as ideias se unem pela associação. Isso ocorreu em uma época em que os homens se congregavam em associações de todo tipo, com base no autorreconhecimento do interesse comum e das mesmas opiniões, não menos do que como base para o engajamento em disputas. Um notório momento de divergência entre Hume e Smith se revela tão pertinente e informativo hoje quanto naquela época (ver Weston, 2018).

O que estava em questão, e eu sigo o relato de Rasmussen (2017: 90-91), era o conceito de "simpatia", então no sentido amplo de companheirismo como uma capacidade humana fundamental. Eles concordavam sobre sua importância. Ao ser afetado pela maneira como outra pessoa parece alegre ou abatida, Hume comparou a transmissão de sentimentos entre as pessoas por meio da simpatia a correntes vibrantes que transmitem movimento de um a outro, um contágio

no uso acadêmico como Di Giminiani e González Gálvez (2018: 202) apontam (ver nota 3). O afável teor de “sociabilidade" (veja abaixo) está entre as razões pelas quais antropólogos e antropólogas têm procurado o termo menos carregado de "socialidade" para fins mais gerais.

13 Deixando de lado as idiossincrasias do inglês a respeito das relações de parentesco. Nem preciso acrescentar que esse tipo de sentimentalização das relações pode gerar sentidos de pertencimento altamente excludentes.

14 Nota da tradutora: o argumento aqui citado encontra-se no seguinte artigo publicado primeiro em português: Viveiros de Castro, Eduardo. 2000. “Atualização e contra-efetuação do virtual na socialidade amazônica: o processo de parentesco". Ilha Revista de Antropologia, 2 (1): 5-46. https://periodicos.ufsc.br/index.php/ilha/article/ view/14635/13384

15 Em correspondência, eles se dirigiram de maneira singular um ao outro, "meu mais caro amigo", um epíteto que nenhum deles usou com outros correspondentes (Rasmussen, 2017: 4). Sou grata a Kath Weston por mencionar esse livro. 
emocional. Em contraste, Smith argumentou que não se pode penetrar nos sentimentos de outras pessoas sem se colocar imaginativamente no lugar delas, desse modo, sendo projetado em uma avaliação de suas circunstâncias e percebendo o que a própria pessoa sentiria ${ }^{16}$. A insistência de Hume ${ }^{17}$ de que deve depender do tipo de sentimento em questão se a simpatia é agradável ou desagradável, suscitou um esclarecimento de Smith. Independentemente da natureza do que é transmitido, declarou ele, "podemos ter prazer com a harmonia dos sentimentos" (grifo meu); a simpatia mútua é intrinsecamente agradável no sentido de que "gostamos naturalmente do sentimento de concórdia emocional" (glosas de Smith feitas em Rasmussen, 2017: 111-110). Em outras palavras, era a maneira como os sentimentos se compatibilizam, a própria relação, que era agradável. "Relação" é minha interpolação aqui. No entanto, quando seus pensamentos estavam em outro lugar, Hume também poderia ter falado sobre "o amor das relações" (frase dele) como uma questão de harmonia. Na medida em que as pessoas "se associam", revelando a simpatia "que sempre surge entre tipos semelhantes", e observam a "semelhança entre si e os outros", a semelhança "opera à maneira de uma relação, produzindo uma conexão de ideias" (Hume, 2000 [1739-40]: 229) $)^{18}$.

Na busca de seus argumentos, e no modo como se baseiam do vernáculo inglês, os filósofos estão criando uma apreciação das relações por meio do que eu chamaria de atmosfera estética. A reiteração do que é semelhante e de acordo em termos do quanto a companhia é agradável e da cordialidade da estreita associação entre coetâneos produz uma dispersão de efeitos. As relações de afeto e o afeto das relações ricocheteiam um no outro. Os atuais falantes de inglês podem não chegar ao ponto de dizer, na língua de Smith, que seja encantador e agradável, mas eles achariam muito apropriado a concórdia implícita em se referir a unir entidades, sejam semelhantes à princípio, ou seja se se tornam semelhantes - comparáveis - em conjunto. Concórdia. Uma premissa de similaridade: uma descrição vernácula das relações, nada menos. Qualquer tensão entre a formulação abstrata e o uso específico desaparece, ainda que apenas por um momento. Em seu lugar está a convicção de uma forma (persuasiva).

\section{De volta}

Voltar a essas formulações históricas, assim como um/a etnógrafo/a pode ser informado/a por eventos passados (por exemplo, Fausto e Heckenberger, 2007), é uma oportunidade que hoje

16 Walker (2020: 149) observa que uma característica específica da sociedade dos semelhantes reside na maneira como "cada indivíduo (...) pode se imaginar na condição de todos os outros indivíduos"; podemos tomar isso como um aspecto da condição mais geral da fraternidade euro-cristã, na qual irmãos ocupam o mesmo ponto de vista sobre o mundo exterior (Viveiros de Castro, 2004: 18) ou, como diz Vilaça (2019: 147), cada um vê a irmã do outro como uma irmã.

17 Smith considerava que tinha melhorado a descrição de Hume da simpatia; Hume posteriormente entrou em correspondência com Smith sobre o assunto.

18 E a conexão pode ser ainda mais investida de sentimentos. Assim, ele continua: “E como (...) um amor ou afeto surge da semelhança, podemos aprender que a simpatia para com os outros é agradável apenas quando dá emoção ao espírito, visto que uma simpatia fácil e emoções correspondentes só são comuns a [os termos para/ o senso de] relação, familiaridade e semelhança" (Hume, 2000 [1739-40]: 229, itálico no original). 


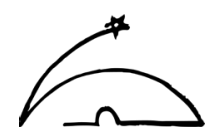

se dá com a interferência de invenções conceituais em mente. Noto o óbvio. Tanto a antropologia ameríndia quanto a melanésia se beneficiaram de correntes alternativas no pensamento euro-americano que recusaram a premissa da similaridade. Porém, no que diz respeito às linguagens analíticas da antropologia, ainda permanece uma dimensão significativa para a tarefa de se fazer a crítica. Pois quem fala e escreve em inglês não escapa facilmente e de uma vez às conotações tenazes que a noção de relação, correndo aqui e ali no entrelaçamento de diversos argumentos e teorias, carrega nas costas.

\section{Agradecimentos}

Sou muita grata ao Comitê Editorial por sugerir que eu escrevesse um pequeno artigo para esse dossiê, e ao editor Lucas da Costa Maciel por me dar uma ideia quanto à ambição e escopo. Os dois pareceristas da revista devem ser agradecidos por seus comentários muito estimulantes. Meu outro agradecimento é a International Balzan Foundation por financiar uma incursão de pesquisa no Center for Pacific Studies, da University of St Andrews, envolvendo materiais da Melanésia e da Amazônia, e sob os auspícios de Virginia Amaral, Simon Kenema e Priscila Santos da Costa por seus comentários.

\section{Referências}

Bonilla, Oiara. 2016. "Parasitism and subjection: Modes of Paumari predation”. In: Brightman, Marc; Fausto, Carlos e Grotti, Vanessa (Org). Ownership and nurture: Studies in native Amazonian property relations. Oxford: Berghahn Books, 110-132.

Costa, Luiz e Fausto, Carlos. 2019. "The enemy, the unwilling guest and the jaguar host: An Amazonian story”. L'Homme (online) 231-232: 195-226. http://journals.openedition.org/lhomme/35579

Crook, Tony. 2007. Exchanging skin: Anthropological knowledge, secrecy and Bolivip, Papua New Guinea. Oxford: OUP for The British Academy.

Di Giminiani, Piergiorgio e González Gálvez, Marcelo. 2018. "Who owns the water? The relation as unfinished objectification in the Mapuche lived world". Anthropological Forum, 28 (3): 199-216. https://doi.org/10.1080/006 64677.2018 .1495060

Fausto, Carlos e Heckenberger, Michael (Org). 2007. Time and memory in indigenous Amazonia: Anthropological perspectives. Gainesville: University Press of Florida.

González Gálvez, Marcelo; Di Giminiani, Piergiorgio e Bacchiddu, Giovanna. 2019. “Theorizing relations in indigenous South America: An introduction”. Social Analysis 63 (2): 1-23. https://doi.org/10.3167/sa.2019.630201 
Holbraad, Martin. 2020. "The shapes of relations: Anthropology as conceptual morphology". Philosophy of the Social Sciences (online): 1-28. https://doi.org/10.1177/0048393120917917

Hume, David. 2000 [1739-40]. A treatise of human nature. Oxford: Oxford University Press.

Lagrou, Els. 2019. “Learning to see in Western Amazonia: How does form reveal relation?”. Social Analysis 63 (2): 24-44. https://doi.org/10.3167/sa.2019.630202

Moutu, Andrew. 2013. Names are thicker than blood: Kinship and ownership amongst the Iatmul, Oxford: OUP for The British Academy.

Rasmussen, Denis. 2017. The infidel and the professor: David Hume, Adam Smith, and the friendship that shaped modern thought. Princeton: Princeton University Press.

Strathern, Marilyn. 1988. The Gender of the Gift: Problems with women and problems with society in Melanesia. Berkeley and Los Angeles: California University Press.

Vanzolini, Mariana. 2019. "The name of the relation: Making a difference in Aweti Onomastics". Social Analysis 63 (2): 101-121. https://doi.org/10.3167/sa.2019.630206

Vilaça, Aparecida. 2019. “Afterword: Relations and relatives”. Social Analysis 63 (2): 143-150. https://doi.org/10.3167/ sa.2019.630208

Viveiros de Castro, Eduardo. 2000. "Atualização e contra-efetuação do virtual na socialidade amazônica: o processo de parentesco". Ilha Revista de Antropologia, 2 (1): 5-46. https://periodicos.ufsc.br/index.php/ilha/article/ view/14635/13384

Viveiros de Castro, Eduardo. 2004. "Perspectival anthropology and the method of controlled equivocation". Tipití 2 (1): 3-22. http://digitalcommons.trinity.edu/tipiti/vol2/iss1/

Viveiros de Castro, Eduardo. 2015. The relative native: Essays on indigenous conceptual worlds. Chicago: HAU Books.

Viveiros de Castro, Eduardo. 2018. "A Antropologia Perspectivista e o método da equivocação controlada". Aceno Revista de Antropologia do Centro-Oeste 5 (10): 247-264. https://periodicoscientificos.ufmt.br/ojs/index.php/aceno/ article/view/8341

Walker, Harry. 2020. "Equality without equivalence: An anthropology of the common". JRAI 26 (1): 146-166. https://

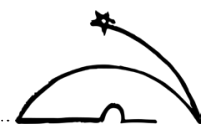




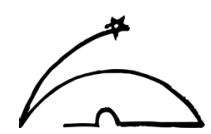

doi.org/10.1111/1467-9655.13183

Weston, Kath. 2018. "The ethnographer's magic as sympathetic magic". Social Anthropology / Anthropologie Sociale, 26 (1): 15-29. https://doi.org/10.1111/1469-8676.12492 